\title{
REFLEXÕES SOBRE A LOUSA DIGITAL COMO RECURSO PEDAGÓGICO A PARTIR DA ABORDAGEM SOCIOINTERACIONISTA
}

\author{
Daniel de Carli, IFRS \\ daniel.carli@bento.ifrs.edu.br \\ Eliana Maria do Sacramento Soares, UCS \\ EMSoares@ucs.br
}

\begin{abstract}
Resumo: Vivemos em uma época de transformações socioculturais advindas da presença das TDs (tecnologias digitais) nas relações humanas. A escola, imersa nesse cenário, não pode desconsiderar que as TDs estão presentes em todas as áreas do conhecimento humano e implicam em novas formas de ser e de estar. Diante disso, o texto apresenta a análise de um recorte do corpus de um estudo de caso que analisa o uso pedagógico da lousa digital em uma turma do $3^{\circ}$ ano do ensino fundamental. Inicialmente, o texto contextualiza o perfil do aluno na contemporaneidade, conceitua os termos TDI (tecnologia digital interativa) e interação, e, posteriormente, com base na Teoria Sociointeracionista de Vygotsky, apresenta uma discussão norteando formas de uso pedagógico da lousa digital.
\end{abstract}

Palavras chave: tecnologias digitais interativas; pedagógico; sociointeracionista; lousa digital.

\section{REFLECTIONS ON THE DIGITAL WHITEBOARD AS A PEDAGOGICAL RESOURCE FROM THE INTERACTIONIST APPROACH}

Summary: We live in a time of socio-cultural transformations resulting from the presence of TDs (digital technology) in human relations. The school, immersed in this scenario, can't disregard that the TDs are present in all areas of human knowledge and involve new ways of being and be. Thus, the paper presents the analysis of a clipping from the corpus of a case study that analyzes the pedagogical use of digital whiteboard in a classroom of the 3rd year of elementary school. Initially, the text contextualizes the student profile in contemporary, defines the terms TDI (interactive digital technology) and interaction, and then based on the Theory Social Interactionist of Vygotsky, presents a discussion guiding ways of pedagogical use of digital whiteboard.

Keywords: interactive digital technologies; pedagogical; sociointeractionist; digital whiteboard.

\section{Cenário contemporâneo}

Vivemos uma época de profundas transformações socioculturais marcadas principalmente pelo advento das tecnologias digitais, (TDs), que promovem mudanças na forma de ser e estar, dos seres humanos. O desafio pedagógico deste início de século será, pois, tentar garantir a primazia da construção do conhecimento, em uma sociedade na qual o fluxo de informação é vasto e abundante. Segundo Prensky (2001), nossos alunos mudaram radicalmente em relação a alunos de anos passados. Segundo Lemos (2008), a cultura contemporânea quando associada às tecnologias digitais cria uma nova 
relação entre a técnica e a vida social chamada de cultura digital ou cibercultura ${ }^{l}$. Assim, podemos dizer que uma nova estética do social cresce sob nossos olhos, alimentada pelas tecnologias do ciberespaço ${ }^{2}$. "[...] as novas tecnologias tornam-se vetores de novas formas de agregação social. A tese do fundo é que a cibercultura resulta da convergência entre a sociedade contemporânea e as novas tecnologias de base microeletrônica". (idem, ibidem, p. 15-16).

Ainda segundo Lemos (2009), há três características que estão na base desse processo cultural, denominado cultura digital. O primeiro diz respeito à liberação do polo emissor, onde o indivíduo passa a emitir sua própria informação; o segundo é o princípio da conexão, pois não basta emitir é necessário estar conectado em rede; e, o terceiro, é consequência dos primeiros que é a reconfiguração sociocultural a partir de novas práticas recombinatórias.

Diante disso, como a escola pode conduzir seus processos educativos diante de alunos que vivem nessa cultura? Em seu artigo - Nativos digitais, imigrantes digitais Prensky (2001) faz uma citação do Dr. Bruce D. Barry da Faculdade de Medicina Baylor que pode responder em parte a esta questão: "Tipos distintos de experiências levam à distintas estruturas de pensamento." Isso significa dizermos que os alunos de hoje pensam e processam as informações de forma bem diferente das gerações anteriores. Estas diferenças vão mais longe e mais intensamente do que muitos educadores suspeitam ou percebem. Tais diferenças não são fruto do acaso, e sim, de uma das mais significativas transformações culturais da história humana onde as TDs são as protagonistas. Portanto, o fato de a escola desconsiderar as características culturais do aluno, que poderiam servir de base pedagógica, sustenta a ideia de Cambi (1999, p.641), quando afirma que a pedagogia contemporânea está em busca de uma nova identidade, em busca de um equilíbrio frente a esta estrutura social em processo de reconfiguração.

\section{Tecnologia digital interativa e interação: esclarecendo conceitos}

Quando tratamos do uso das tecnologias digitais aplicadas ao processo de ensino-aprendizagem, é da interação do aluno com o conteúdo de estudo mediado pela tecnologia que tratamos. Dessa forma, passaremos a utilizar o termo tecnologia digital interativa (TDI), uma vez que a interação tem papel fundamental ao tratarmos do uso pedagógico da lousa digital numa abordagem sociointeracionista.

Em Silva (2002), acabamos encontrando uma definição mais convincente sobre o termo interatividade. Este sociólogo que se esmerou em desvelar o surgimento do termo, diferentemente do que muitos imaginam, é surgido na década de 1970 na área da comunicação e não da informática. Tal expressão buscava a bidirecionalidade entre emissão e recepção, proporcionando uma comunicação mais aberta e criativa que potencializava as trocas entre os polos.

Diante disso, a interatividade pode ser entendida como um conjunto de ações/reações, locuções/interlocuções que podem se dar em qualquer área da comunicação humana, na relação pessoa-pessoa ou pessoa-tecnologia conforme afirma Silva (2002, p. 20):

“interatividade é a disponibilização consciente de um mais comunicacional de modo expressivamente complexo, ao mesmo tempo atentando para as

\footnotetext{
1 Cibercultura é uma forma de cultura surgida junto com o desenvolvimento das tecnologias digitais, o ermo cibercultura provém da junção das palavras cibernética e cultura. Designa cultura digital.

2 O ciberespaço é definido como "o espaço de comunicação aberto pela interconexão mundial dos computadores e das memórias dos computadores” (LÉVY, 1999, pág. 92)
} 
interações existentes e promovendo mais e melhores interações - seja entre usuário e tecnologias, digitais ou analógicas, seja nas relações "presenciais" ou "virtuais" entre os seres humanos."

Para este texto, trataremos do termo interatividade ou interativo, como sendo uma característica das TDIs no sentido de promover mais e melhores interações.

Quanto ao termo interação, associado à abordagem sociointeracionista, será utilizado com base nos conceitos utilizados na área da psicologia e da computação pela relação destas com o presente estudo. O quadro abaixo demonstra o conceito relacionado às respectivas áreas.

Tabela 1 - Conceito de interação dividido pelas áreas da psicologia e da computação. Fonte: os autores.

\begin{tabular}{|c|c|}
\hline Área & Conceito de Interação \\
\hline Psicologia & $\begin{array}{c}\text { "duas entidades influenciando simultaneamente o comportamento de } \\
\text { cada uma delas, numa dada situação".(SOULA, BARON, NESTOR, } \\
\text { 1997, p. 7) }\end{array}$ \\
\hline Computação & $\begin{array}{c}\text { "relação entre a pessoa e a máquina, processo que acontece quando uma } \\
\text { pessoa opera uma máquina, tipo de controle". (JENSEN, 1998, p. 190) }\end{array}$ \\
\hline
\end{tabular}

Diante dessa visão, trataremos da relação humano - humano e humano - TDI como interação (ação de interagir), considerando sempre que as TDIs são tecnologias digitais que possuem características interativas que possibilitam interações mais complexas devido ao "mundo" de recursos e possibilidades que apresentam principalmente quando conectadas à internet, por exemplo.

\title{
3 Contextualizando a lousa digital
}

Diante de um levantamento de estudos realizados acerca do uso pedagógico da lousa digital, foram selecionados os que apresentaram maior relevância para o nosso estudo. Dentre os pesquisados, destacamos a definição de lousa digital segundo Gomes (2010, p.61):

\begin{abstract}
A lousa digital interativa é um recurso tecnológico que possibilita o desenvolvimento de atividades pedagógicas, fazendo uso de imagens, textos, sons, vídeos, páginas da internet, dentre outras ferramentas, cujo quadro tem o tamanho aproximado de setenta e oito polegadas ${ }^{3}$, que deve necessariamente estar ligada a uma unidade central de processamento (CPU) do computador, o qual deverá estar conectado a um projetor multimídia. Todo o conteúdo a ser apresentado na lousa digital deverá estar armazenado na memória do computador, que será transmitido na lousa digital por meio do projetor multimídia. [...] Proporciona a professores e alunos interagirem com o conteúdo e atividades expostas na lousa e com as ferramentas apresentadas por ela, utilizando apenas o toque de um dedo na lousa, o que proporciona uma interatividade maior entre o professor e o aluno, entre os próprios alunos e destes com as informações contidas na aula que foi preparada pelo professor.
\end{abstract}

Para Nakashima (2008), a lousa digital é uma tecnologia com recursos que podem auxiliar na criação de estratégias pedagógicas de aprendizagem. Atualmente, existem vários modelos de lousas digitais, variando a marca e o custo, mas a maior parte

3 Polegada é uma unidade de comprimento usada no sistema imperial de medidas britânico. Uma polegada corresponde a 2,54 centímetros. 
delas é composta por uma tela digital interativa com tecnologia touchscreen ${ }^{4}$ em que se pode interagir com seu conteúdo pelo simples toque do dedo. Com o simples toque na tela, o computador reage executando o movimento digitalmente por meio de um software (programa de computador) específico que acompanha a lousa digital.

O software da lousa digital oferece recursos que a tornam um instrumento de TDI com um grande repertório de possibilidades de uso. Acerca dos recursos de software da lousa digital, podemos dizer que é possível fazer anotações ou desenhar sobre qualquer conteúdo exibido em sua tela como: páginas da Internet, documentos de texto, planilhas eletrônicas, conteúdo em forma de apresentações e até mesmo fazer anotações sobre vídeos pausados para destacar algo que seja oportuno. Além disso, dispõe de uma vasta galeria de objetos interativos divididos por áreas do conhecimento humano. Nesse sentido, além dos próprios recursos, a lousa digital se constitui em um instrumento que estende em seu plano, muitas das funcionalidades presentes no computador além de estar conectada à internet. Segundo Nakashima e Amaral (2006), um dos benefícios trazidos da lousa digital interativa é o fato dela ser uma tecnologia "híbrida", que incorpora vários recursos que podem ser potencializadores de situações de aprendizagem. Aliada a isso, a lousa digital é um dos poucos instrumentos de TDI que foi desenvolvido basicamente para fins didáticos. Nesse sentido, a utilização da lousa digital pelo professor, poderá possibilitar que ele desenvolva atividades com vários recursos em um único equipamento, desde que, como destaca Amaral e Barros (2007), um projeto pedagógico para suportar as práticas educativas para uso da lousa digital seja pensado.

\section{Elementos marcantes da abordagem sociointeracionista}

Para refletir sobre o uso pedagógico da lousa digital, tomamos a abordagem sociointeracionista de Vygotsky como base teórica, mais especificamente os conceitos de interação, mediação e zona de desenvolvimento proximal (ZDP).

Ao tratarmos da abordagem sociointeracionaista, nosso olhar teórico propõe que enxerguemos todos os que participam do processo educativo como sujeitos inseridos em um momento histórico, provenientes de um grupo social, de uma classe e de uma cultura, dentro dos quais transformam e são transformados pelas constantes interações sociais. Nessa perspectiva, segundo Matui (1995), a essência humana se constitui pelo relacionamento social humano, pelas interações sociais. Dessa forma, torna-se impossível considerar o desenvolvimento do sujeito como um processo previsível, universal e linear, mas o que podemos afirmar é que o desenvolvimento está associado ao contexto sociocultural no qual o indivíduo se insere, e o mesmo se processa de forma dinâmica, resultado dos desequilíbrios ocasionados pelas constantes relações sociais. $\mathrm{O}$ desenvolvimento, segundo Vygotsky (1998), é construído, em parte, pelo processo de maturação do sujeito, por meio das influências sociais, mas é a aprendizagem que possibilita o despertar dos processos internos de desenvolvimento. Assim, o desenvolvimento é percebido de forma entrelaçada às praticas sociais e educativas, incluindo, então, necessariamente o processo de aprendizagem.

Desenvolvimento e aprendizagem dizem respeito às experiências do indivíduo no mundo com base nas interações, assumindo o pressuposto da natureza social do desenvolvimento e do conhecimento especificamente humano. Vygotsky (1998, p.110) afirma que o aprendizado começa muito antes da criança frequentar a escola e toda e

4 É um tipo de tela sensível à pressão pelo uso do próprio dedo ou a outro instrumento para determinado fim, dispensando assim, a necessidade de outro periférico de entrada de dados, como o teclado por exemplo. 
qualquer situação de aprendizado com o qual a criança se defronta na escola tem uma historicidade prévia. Vygotsky reconhece que o aprendizado deve ser coerente com o desenvolvimento sendo que o "bom aprendizado" é somente aquele que se adianta ao desenvolvimento.

Para Vygotsky (1998), a mediação é o processo pelo qual a ação do sujeito sobre o objeto é mediada por um determinado elemento. Ainda segundo Vygotsky, a mediação compreende o processo de intervenção de um elemento intermediário numa relação, esta deixa de ser direta e passa a ser mediada por ferramentas, que segundo ele, são divididas em duas categorias: instrumentos e signos. Vigotsky (1998) entende que o homem possui um duplo nascimento: o biológico e o cultural. A inserção na cultura, pela interação com o outro via linguagem, é o que possibilita ao indivíduo se tornar de um simples ser biológico um ser cultural. Nesse sentido, a função do instrumento é servir como mediador da influência humana sobre o objeto da atividade; ele deve necessariamente levar a mudanças nos objetos.

Os signos também são mediadores, porém sua função se faz presente na atividade psicológica do indivíduo, por esta razão Vygotsky os denomina ferramentas ou instrumentos psicológicos. À medida que o indivíduo internaliza os signos que controlam as atividades psicológicas, ele cria os sistemas simbólicos que são estruturas de signos articuladas entre si. O uso de sistemas simbólicos, como a linguagem, por exemplo, favoreceu o desenvolvimento social, cultural e intelectual dos grupos culturais e sociais ao longo da história.

Para que o desenvolvimento cognitivo do indivíduo seja potencializado, é necessário atuar em uma zona além do nível de conhecimento real do indivíduo que é a chamada zona de desenvolvimento real, (ZDR). Este "além no nível real de desenvolvimento" é o que Vygotsky chama de zona de desenvolvimento proximal (ZDP), que compreende o espaço de trabalho no qual uma pessoa atua para ampliar os conhecimentos do aprendiz. Mas qual é o limite da ZDP? O limite é

\footnotetext{
"a distância entre o nível de desenvolvimento real, que se costuma determinar através da solução independente de problemas, e o nível de desenvolvimento potencial, determinado através da solução de problemas sob a orientação de um adulto ou em colaboração com companheiros mais capazes.” (Vygotsky, 1998, p. 112).
}

A ZDR não é estática, muito pelo contrário, o que hoje está na ZDP espera-se que "amanhã" seja a ZDR, resultando dessa forma, no desenvolvimento cognitivo do indivíduo. Assim, a ZDP refere-se à solução de problemas que o aluno não vai resolver de forma independente, são as funções que estão em processo "embrionário" e que se tornarão funções consolidadas, estabelecidas no seu nível de desenvolvimento real. Como afirma Vygotsky (1998, p.113), "essas funções poderiam ser chamadas de "brotos" ou "flores" do desenvolvimento, ao invés de "frutos" do desenvolvimento. Estes "brotos" ou "flores" não crescem ou desabrocham sem a interação social de outros da mesma espécie".

\section{Percurso metodológico}

Hoje, o número de escolas da rede pública e particular que possuem lousas digitais em sala de aula vem crescendo dia após dia. Sendo assim, apresentamos o recorte de uma pesquisa que esta sendo desenvolvida junto ao PPGEdu da UCS, que tem como questão norteadora "a lousa digital esta sendo utilizada no sentido de proporcionar o desenvolvimento cognitivo do aluno no processo de ensino-aprendizagem?" 
Essa pesquisa está delineada a partir de um estudo de caso do uso pedagógico da lousa digital com alunos do $3^{\circ}$ ano do ensino fundamental de uma escola da rede pública municipal. $\mathrm{O}$ instrumento entrevista individual semiestruturada foi utilizado com quatro professores os quais serão identificados como PE1, PE2, PE3 e PE4. Para esse texto, foram selecionadas as respostas dos professores, que transcritas, foram analisadas segundo procedimentos da análise textual discursiva de Moraes e Galiazzi (2007).

Esses autores tratam o processo da análise textual discursiva como uma "tempestade de luz" que consiste em criar as condições de formação dessa tempestade em que, emergindo do meio caótico e desordenado, formam-se "flashes" fugazes de raios de luz sobre os fenômenos investigados, que, por meio de um esforço intenso de comunicação, possibilitam expressar novas compreensões atingidas ao longo da análise.

De posse do corpus transcrito, iniciamos a unitarização que segundo Moraes e Galiazzi (2007), tem como tarefa a desmontagem dos textos, também chamada de desconstrução. A unitarização ocorreu pelo olhar teórico dos conceitos de mediação, interação e de zona de desenvolvimento proximal de Vygotsky.

Da desconstrução textual emergiram algumas categorias, conforme tabela abaixo, que serão em seguida relacionadas e discutidas.

Tabela 2 - Categorias emergentes. Fonte: os autores

\begin{tabular}{|c|c|}
\hline Categoria Emergente & Observáveis \\
\hline \multirow{2}{*}{$\begin{array}{l}\text { Uso enraizado na } \\
\text { transmissão de conteúdos }\end{array}$} & PE1 - "acostumados ao quadro, você escreve e apaga" \\
\hline & $\begin{array}{l}\text { PE2 - "eles me acordando que eu não tinha percebido } \\
\text { que dava para jogar na lousa digital" }\end{array}$ \\
\hline \multirow{2}{*}{$\begin{array}{l}\text { Interesse em explorar os } \\
\text { recursos interativos }\end{array}$} & PE4 - "estamos explorando os recursos da lousa digital" \\
\hline & PE1 - "nós temos horas de estudo, a gente treina" \\
\hline \multirow{2}{*}{ Necessidade do desafio } & $\begin{array}{l}\text { PE4 - "eles gostam mais do desafio, de resolver algo } \\
\text { mais emocionante" }\end{array}$ \\
\hline & $\begin{array}{l}\text { PE3 - "você deve estar bastante preparado e ser bem } \\
\text { criativo, provocar a criança" }\end{array}$ \\
\hline \multirow{2}{*}{$\begin{array}{l}\text { Ressignificação no papel } \\
\text { dos envolvidos }\end{array}$} & $\begin{array}{l}\text { PE1 - "agita no sentido de eles falarem mais entre eles, } \\
\text { comentarem o que é feito na lousa digital quando o } \\
\text { professor interage na lousa digital" }\end{array}$ \\
\hline & $\begin{array}{l}\text { PE3- "enquanto um interage na lousa os outros ficam } \\
\text { muito atentos no que o colega vai fazer para dizer se está } \\
\text { certo está errado" }\end{array}$ \\
\hline
\end{tabular}

\section{Construindo relações e discussões}

Buscando relacionar as categorias emergentes identificadas à luz dos conceitos do quadro teórico, podemos inferir que o uso da lousa digital, no processo de ensinoaprendizagem, ainda está enraizado na forma vigente de ensinar, baseada apenas na transmissão de conteúdos ao aluno. Isso ficou evidenciado nas verbalizações de PE3 ao falar sobre o uso da lousa digital: "as crianças se interessam mais no copiar, pra ti explicar facilita, não que no quadro comum você não faça, você faz tudo". Essa transmissão, em nosso modo de ver, incorre em alguns problemas, entre os quais, destacamos a não consideração do desenvolvimento cognitivo pré-adquirido do aluno 
como referência de atuação pedagógica, e, na possível inibição da criatividade e da autonomia ligadas à produção e emissão da informação, que, de acordo Lemos (2009), essa produção e emissão se traduzem na liberação do polo emissor, sendo a primeira característica dessa nova cultura digital.

O fato de o professor possibilitar a participação efetiva do aluno nas atividades pedagógicas pelo uso da lousa digital, flexibilizando novas formas do aluno criar aplicando seus conhecimentos cognitivos pré-adquiridos, representa um grande passo no sentido de minimizar os problemas antes apontados, além de possibilitar que o professor conheça melhor o nível de desenvolvimento real do aluno na medida em que observa seus limites diante da prática orientada. É nesse momento que o professor assume a verdadeira função de mediar intervindo com problematizações que se adiantem ao desenvolvimento do aluno, transformando as atividades propostas no "bom aprendizado", termo utilizado por Vygotsky (1998, p.117).

Contrastando com a categoria emergente uso enraizado na transmissão de conteúdos, identificamos, em algumas das atividades trabalhadas pelo uso da lousa digital, a ressignificação no papel dos envolvidos onde o professor proporcionou ao aluno, a oportunidade de trabalhar a atividade diretamente na lousa digital. Uma das atividades foi identificada nas verbalizações de PE1: "em cima de um estudo teórico com palestras e cartazes que foi feito fora da sala de aula, cada um deles devia demonstrar como utilizar a água, aonde utilizar e porque a água é importante [...] na lousa digital daí ele escreve, enfeita, desenha, cria, e os outros vão acompanhando, um não podia repetir o que o colega já fez".

O resultado da atividade foi a participação mais efetiva do aluno e o surgimento de interações coletivas sob orientação do professor. Segundo o professor, a atividade envolveu o aluno, provocando-o a pensar e a representar na lousa digital formas alternativas de utilização da água pela possível associação de práticas já conhecidas deste com as transmitidas em sala de aula na medida em que algumas não poderiam mais ser representadas por regra da atividade. A lousa digital, nesse caso, desempenhou importante papel de mediar a interação do aluno com o conteúdo, ampliando o número de possibilidades de representação do uso da água a um nível em que o limite é a capacidade de criatividade e de exploração dos recursos da lousa digital pelo aluno somada à orientação do professor.

Partindo disso, pode-se inferir que a ressignificação dos papéis não foi planejada ou adotada como estratégia pedagógica, pois, em momento algum foram identificadas evidências dessa intencionalidade nas verbalizações dos professores. A ressignificação, em nosso entendimento, resultou de dois fatores: a oportunidade dada ao aluno de trabalhar a atividade na lousa digital que é um instrumento que desperta seu interesse conforme verbalização de PE4: "a lousa digital chama muito mais atenção"; e, no momento em que o professor se descaracteriza, se esvazia de sua autoridade pedagógica assumindo o papel de mediador identificado nas verbalizações de PE4: " nos momentos em que eles vão na lousa digital temos que ficar orientando".

Para Vygotsky (1998), a aprendizagem ocorre pela interação com o outro. Esse outro pode ser entendido, para este texto, como o colega, o professor, a lousa digital e até o próprio conteúdo de estudo do aluno. A aprendizagem acontece por meio da internalização, a partir de um processo anterior de troca que possui uma dimensão coletiva. Segundo o autor, a aprendizagem deflagra vários processos internos de desenvolvimento mental, que tomam corpo somente quando o sujeito interage com objetos e sujeitos em cooperação. Uma vez internalizados, esses processos tornam-se parte das aquisições do desenvolvimento. Portanto, pela ressignificação de papéis ocorrida, emergiram elementos que no contexto sociointeracionista são indispensáveis 
para a promoção do desenvolvimento cognitivo do aluno quando tratamos do uso pedagógico da lousa digital.

Além da ressignificação dos papéis dos envolvidos, constatamos algumas movimentações em prol do redimensionamento das práticas docentes. O interesse em explorar mais profundamente os recursos interativos da lousa digital, principalmente para suprir demandas dos alunos por atividades mais interessantes e desafiadoras, foi um dos pontos identificados que revelou essa movimentação. Os professores reconheceram que a lousa digital não faz a diferença por si só, mas que depende da postura pedagógica do professor. Nesse sentido, PE1 afirma que "se você vai lá para fazer uma continha é a mesma coisa que um quadro velho, tem que ser uma proposta que desafie, eles gostam de desafios".

Essa maior apropriação e utilização dos recursos interativos da lousa digital, possivelmente, permitirá ao professor a elaboração de atividades pedagógicas mais interessantes em resposta às demandadas do aluno conforme categoria emergente "necessidade do desafio". Pelas verbalizações dos professores, as atividades desafiadoras são apontadas pela maioria como fator determinante no interesse do aluno em participar mais intensamente das atividades que são trabalhadas pelo uso da lousa digital, "eles gostam mais do desafio, de resolver algo mais emocionante" (PE4).

Nesse sentido, é importante destacarmos aqui que, apesar da maioria dos professores ter apontado a necessidade do desafio como fator determinante na participação mais intensa do aluno nas atividades de uso da lousa digital, não basta que estas sejam desafiadoras. Em nossa concepção, é necessário que sejam utilizados recursos da lousa que sejam interessantes ao aluno como imagens, a linguagem audiovisual, jogos etc. Torff e Tirotta (2010) desenvolveram uma pesquisa nos Estados Unidos sobre o uso da lousa digital em aulas de matemática, obtendo o relato dos alunos sobre a sua utilização. Eles relataram que o uso da lousa digital deixou as aulas mais motivadoras e interessantes, o que ajudou os alunos a se concentrarem mais no conteúdo ministrado.

Em se tratando das séries iniciais do ensino fundamental é muito importante destacarmos a importância do uso de atividades lúdicas. Para Rego (2001, p.79), o uso dos jogos proporciona "ambientes desafiadores, capazes de estimular o intelecto proporcionando a conquista de estágios mais elevados do raciocínio". De acordo com esta colocação, o uso de jogos no cotidiano da sala de aula proporciona um riquíssimo instrumento pedagógico, visto que precisa ser praticado, na maioria das vezes em grupos que podem ser heterogêneos, nos quais a troca de experiências ocorre naturalmente e a mediação do professor entre o conhecimento e o aluno também se constitui verdadeira promotora de aprendizado. Nesse sentido, o jogo não pode ser visto pelo professor com preconceito excluindo-o das práticas pedagógicas, porém, precisa estar vinculado ao conteúdo trabalhado tirando proveito pedagógico também das diferentes operações cognitivas que se desenvolvem pelo jogar.

Segundo Pfutzenreuter e Stano (2008), podemos citar ou identificar no mundo do jogo, os recursos e as regras; decodificar símbolos buscando entender seu significado; comparar sua situação atual com a que pretende chegar; projetar passos visando o objetivo; representar mentalmente os diversos elementos do jogo e fazer raciocínio divergente para ter diferentes ideias de como chegar ao objetivo.

Pelas verbalizações de PE2, "o jogo do coelho envolvia matemática e o jogo da Alice no país das maravilhas de lógica, pela historinha eles vão aprendendo matemática ou lógica, por exemplo, a gente pesquisa na Internet e já acessa o jogo". Diante disso, é possível perceber a consciência do professor pela importância do jogo no processo de ensino-aprendizagem e como é possível relacionar atividades que sejam 
interessantes e desafiadoras ao aluno com conteúdos de estudo. O jogar com regras, segundo Vygotsky (1998, p. 125), está presente desde o fim da idade pré-escolar e se desenvolve durante a idade escolar. Ainda segundo o autor, é no brinquedo, no jogo que a criança aprende a agir numa esfera cognitiva ao invés de uma esfera visual externa, dependendo das motivações e tendências internas e não dos incentivos fornecidos pelos objetos externos, sendo que a brincadeira cria para a criança uma ZDP. Dessa forma, pelo jogo é possível combinar experiências passadas com novas possibilidades, interpretações e reproduções do real de acordo com suas necessidades e desejos, se constituindo, assim, em ações fundamentais para seu desenvolvimento cognitivo e despertando, sobretudo, a criatividade.

\section{Considerações finais}

Vivemos um processo de transição, no qual práticas educativas que possam realmente trazer bons resultados ao processo de ensino-aprendizagem pelo uso das TDIs são discutidas. Todas essas discussões incorrem em reflexões no fazer educacional, e, se bem fundamentadas teoricamente, e por pesquisas direcionadas às práticas de uso das TDIs, possivelmente, colocarão a escola no caminho mais indicado para que a sua pedagogia realmente encontre uma identidade que corresponda aos anseios dessa nova sociedade.

O que nos foi possibilitado levantar do uso pedagógico da lousa digital é que ainda há, em grande parte, um uso voltado para a transmissão de conteúdos onde o professor pouco explora os recursos interativos da lousa digital em suas atividades pedagógicas, e, o aluno pouco ou nada participa, apenas assiste. Por outro lado, também identificamos que em algumas das atividades ocorreu uma ressignificação no papel dos envolvidos. Esta ressignificação foi motivada por uma postura pedagógica menos autoritária do professor que proporcionou a participação mais efetiva do aluno na atividade interagindo com o conteúdo de estudo pelo uso da lousa digital. Disso, resultou uma reorganização onde o professor assumiu um papel de mediador e o aluno passou a interagir mais, principalmente com seus pares.

Pelo relacionamento das categorias, podemos identificar também, que o professor está se conscientizado da importância em explorar melhor os recursos interativos da lousa digital principalmente como necessidade de atender às demandas dos alunos por atividades que sejam mais interessantes e desafiadoras. Não descartamos que essa conscientização, por parte do professor, possa ter emergido das reflexões desencadeadas pela realização da entrevista individual no momento em que as questões da entrevista lhe foram dirigidas.

Partindo destas considerações, do que foi identificado pelas verbalizações dos professores e baseados na abordagem sociointeracionista, propomos alguns norteadores como forma de contribuir para que o processo de ensino-aprendizagem pelo uso da lousa digital em sala de aula realmente possa refletir num melhor desenvolvimento cognitivo do aluno:

a) o professor precisa permitir que o aluno participe da atividade pedagógica interagindo pelo uso da lousa digital; individualmente ou em grupo;

b) é necessário que o professor oriente o aluno na atividade de uso da lousa digital buscando conhecer os limites de desenvolvimento deste em relação à atividade, possibilitando dessa forma, conhecer sua ZDR para explorar a ZDP;

c) o professor precisa levar em consideração as características do aluno dessa nova cultura digital nas atividades pedagógicas que a lousa digital é utilizada; 
d) o papel do professor precisa focar a orientação da atividade abandonando sua autoridade pedagógica, proporcionando dessa forma, maior autonomia do aluno na atividade com o intuito de provocar um maior número de interações sociais sobretudo; e,

e) o professor precisa associar o interessante para o aluno e/ou atividades que o desafiem ao conteúdo de estudo, buscando dessa forma, um ponto de equilíbrio que possibilite um processo de ensino-aprendizagem mais interessante para todos os envolvidos.

Todavia, para que estas práticas pedagógicas possam acontecer, é necessário que todos os envolvidos no processo educacional - corpo diretivo, corpo administrativo e corpo docente - estejam empenhados e preparados para superar dificuldades que certamente se farão presentes. Na escola em que os professores entrevistados atuam, foi possível identificar, pelas verbalizações dos professores, que há de fato um trabalho conjunto nesse sentido. Esse envolvimento coletivo, aliado aos indicadores que puderam ser apontados como positivos, constituem um grande passo que contribui para tornar a lousa digital um instrumento capaz de alavancar o processo de ensinoaprendizagem no contexto dessa nova cultura neste início de século XXI.

\section{Referências Bibliográficas}

AMARAL, S. F.; BARROS, D. M. V. Estilos de Aprendizagem no contexto educativo de uso das tecnologias digitais interativas. Campinas: UNICAMP, 2007. Disponível em: <http://lantec.fae.unicamp.br/lantec/pt/tvdi_portugues/daniela.pdf>. Acesso em 05 ago. 2013.

CAMBI, F. História da pedagogia. São Paulo: Fundação Editora da UNESP, 1999.

GOMES, E. M. Desenvolvimento de atividades pedagógicas para a educação infantil com a lousa digital interativa: uma inovação didática. Campinas: [s.n.], 2010.

JENSEN, J. F. Interactivity - Tracking a new concept in media and communication studies. 1998. Disponível em <http://www.nordicom.gu.se/common/publ_pdf/38_jensen.pdf. Acesso em: 10 mar. 2013.

LEMOS, A. A cibercultura e seu espelho: Campo de conhecimento emergente e nova vivência humana na era da imersão interativa. São Paulo: ABCiber, Itaú Cultural, CAPES, 2009.

LEMOS, A. Cibercultura: tecnologia e vida social na cultura contemporânea. Porto Alegre: Sulina, 2008.

LÉVY, P. Cibercultura. São Paulo: Editora 34, 1999.

MATUI, J. Construtivismo: teoria construtivista sócio-histórica aplicada ao ensino. SP: Moderna, 1995.

MORAES, R.; GALIAZZI, M. C. Análise textual discursiva. Ijuí: Editora UNIJUÍ, 2007. 
NAKASHIMA, R. H. R. A linguagem interativa da lousa digital e a teoria dos estilos de aprendizagem. Campinas: [s.n.], 2008.

NAKASHIMA, R. H. R.; AMARAL, S. F. A linguagem audiovisual da lousa digital interativa no contexto educacional. Revista Educação Temática Digital. v. 8, n.1, p. 33-50, 2006.

Revista Educação Temática Digital. v. 8, n.1, p. 33-50, 2006.

PFUTZENREUTER, E. P; STANO, R. C. Jogo como elemento mediador no processo de construção de conhecimento no espaço universitário. In: IV Seminário Jogos, Educação e Comunicação; Construindo Novas Trilhas, Salvador, BH: 2008.

PRENSKY, M. Digital natives, digital immigrants. MCB University Press, 2001.

SILVA, M. Sala de aula interativa. Rio de Janeiro: Quartet, 2002.

REGO, T. C. Vygotsky: Uma perspectiva histórico-cultural da educação. 11. ed. Petrópolis: Vozes, 2001.

SOULA, J. P.; BARON, C.; NESTOR, C. A shift from chalk: multimedia and instruction. IEEE MultiMedia, Washington, v. 4, n. 2, p. 5-9, 1997.

TORFF, B.; TIROTTA, R. Interactive Whiteboards Produce Small Gains in Elementary Students' Self-Reported Motivation in Mathematics. Computers \& Education. Retrieved from ERIC database, Oxford, UK, v. 54, p. 379-383, 2010.

VYGOTSKY, L. S. A Formação Social da Mente. 6. ed. São Paulo: Martins Fontes, 1998. 